\title{
Sense of Coherence and Four-Year Caries Incidence in Finnish Adults
}

\author{
E. Bernabéa ${ }^{a}$ J.T. Newton ${ }^{b}$ A. Uutela ${ }^{c}$ A. Aromaa ${ }^{c}$ A.L. Suominen ${ }^{\text {c-e }}$ \\ a Unit of Dental Public Health, and ' ${ }^{b}$ Unit of Social and Behavioural Sciences, King's College London Dental Institute, \\ London, UK; ' ${ }^{C}$ National Institute for Health and Welfare (THL), Helsinki, d Department of Oral Public Health,

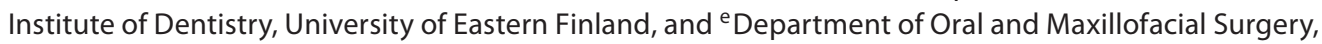 \\ Kuopio University Hospital, Kuopio, Finland
}

\section{Key Words}

Adults · Dental caries $\cdot$ Finland $\cdot$ Longitudinal study ·

Psychosocial factors

\begin{abstract}
This study assesses whether sense of coherence (SOC) predicts incidence of tooth decay over 4 years and the role of dental behaviours in explaining the effect of SOC on incidence of tooth decay. Data from 994 adults who participated in both the Health 2000 survey and the Follow-Up Study of Finnish Adults' Oral Health were analysed for this study. At baseline, participants provided information on demographic characteristics, education level, the SOC scale and dental behaviours (tooth brushing frequency, dental attendance and sugar intake frequency). The 4-year incidence of tooth decay was calculated using data from baseline and followup clinical oral examinations. Baseline SOC was significantly related to 4-year incidence of tooth decay after adjustment for demographic factors and education (relative risk: 0.79 , 95\% Cl: 0.63-0.98). This effect was fully attenuated after further adjustment for the three dental behaviours. Tooth brushing frequency and dental attendance were the only dental behaviours significantly related to incidence of tooth
\end{abstract}

decay. This prospective study suggests that $\mathrm{SOC}$ predicts incidence of tooth decay and that dental behaviours may help explaining why adults with strong SOC have lower risk of developing tooth decay than those with weak SOC.

Copyright $\odot 2012$ S. Karger AG, Basel

The salutogenesis theory refers to the origins of health rather than disease, and focuses on resources for maintaining health and health-promoting processes [Antonovsky, 1987, 1996]. By asking why people are healthy or why they remain healthy despite experiencing adversity and stressful situations, researchers may start identifying pathways leading to health. Antonovsky's [1987, 1996] sense of coherence (SOC) construct is the very core of the salutogenesis theory and relates to the way individuals make sense of the world - comprehensibility -, use required resources to respond to it - manageability - and feel that these responses are meaningful and make sense emotionally - meaningfulness [Antonovsky, 1987]. As such, SOC represents the capacity to turn available resources, flexibly and proactively, to meet the demands posed by stressors. Supporting the contribution of SOC to health, various prospective studies have shown that

\section{KARGER}

Fax +41613061234 E-Mail karger@karger.ch www.karger.com
(C) 2012 S. Karger AG, Basel

$0008-6568 / 12 / 0466-0523 \$ 38.00 / 0$

Accessible online at:

www.karger.com/cre
Dr. Eduardo Bernabé

Unit of Dental Public Health, King's College London Dental Institute

Denmark Hill Campus, Caldecot Road

London SE5 9RW (UK)

Tel. +44 203299 3022, E-Mail eduardo.bernabe@kcl.ac.uk 
stronger SOC predicts better health outcomes in adult life [Poppius et al., 1999; Kivimäki et al., 2000; Suominen et al., 2001; Poppius et al., 2003; Surtees et al., 2003; Kouvonen et al., 2008, 2010]. Similarly, some cross-sectional studies have found that adults with strong SOC exhibit more teeth and lower levels of dental caries and periodontal disease than their counterparts [Bernabé et al., 2010; Lindmark et al., 2011a; Bernabé et al., 2012].

SOC may promote health through three different pathways: first, by regulating emotional tension generated by confrontation with stressors; second, through the selection of health-promoting behaviours, and third, by direct physiological consequences via the central pathways of the neuroimmune and endocrine systems [Antonovsky, 1987, 1996]. The behavioural pathway of SOC seems relevant to most oral diseases as they have a strong behavioural component. SOC may influence the aetiology of, and recovery from disease through effective coping, by avoiding behaviours that are directly detrimental to health such as smoking, excessive drinking, unhealthy diet or sedentary lifestyle, and by adopting behaviours that can reduce the severity of illness, such as seeking treatment early or compliance to it [Antonovsky, 1996]. Indeed, prior research in adults has shown that a strong SOC is related to more favourable dental behaviours [Savolainen et al., 2004; Lindmark et al., 2005; Savolainen et al., 2005; Bernabé et al., 2009a; Savolainen et al., 2009; Lindmark et al., 2011b]. Longitudinal studies may help to examine this novel research area in greater depth. Therefore, this study explores whether SOC predicts incidence of tooth decay over 4 years and the role of dental behaviours in explaining the effect of SOC on incidence of tooth decay in Finnish dentate adults.

\section{Subjects and Methods}

\section{Data Source}

The Health 2000 Survey was a national survey conducted by the National Institute for Health and Welfare (THL, formerly the National Public Health Institute) in 2000-2001. The stratified two-stage cluster sample was representative of the Finnish national population and included 8,028 subjects aged 30 years or over. The sample size was determined so that it allowed investigation of the prevalence of most health problems by sex and age groups [Aromaa and Koskinen, 2004]. A total of 7,419 subjects ( $93 \%$ of the 7,977 subjects alive on the first day of the survey) participated in at least one phase of the survey and 6,335 subjects (79\%) had clinical oral examinations [Aromaa and Koskinen, 2004; Heistaro, 2008]. In 2000, THL launched a series of population studies in collaboration with the Social Insurance Institution of Finland (KELA) to evaluate the effects of the dental care reform implemented in Finland in 2001-2002. To assess the short-term effects of the reform on clinically determined oral health, the Follow-Up Study on Finnish Adults' Oral Health was conducted in 2004-2005. For this survey, 2,000 subjects were randomly selected from the list of participants who had attended the clinical oral health examinations in the Health 2000 Survey. Dead, edentulous and those in health centre districts where less than 15 subjects had been sampled (for logistic reasons) were excluded. The final sampling frame of the follow-up examinations comprised 1,248 subjects who were invited to a clinical oral re-examination. The participation rate of the follow-up examinations was $84 \%(n=1,049)$.

The present study is based on 944 dentate adults who participated in both surveys and had complete data on the variables selected for analysis. The length of follow-up was approximately 4 years (mean: 1,504 days; range: 1,327-1,696).

\section{Variables}

At baseline, participants provided information on their demographic characteristics, education, SOC scale and dental behaviours. Education was measured by the number of years of fulltime education and classified as basic (0-9 years), secondary (9-12 years) or higher education (13+ years).

Participants' SOC was assessed using a slightly abbreviated version of the Finnish SOC-13 scale [Savolainen et al., 2004, 2005; Bernabé et al., 2009a; Savolainen et al., 2009; Bernabé et al., 2010]. The item 'Does it happen that you have feelings inside you would rather not feel?' belonging to the comprehensibility component was not included in the final questionnaire of the Health 2000 Survey. Participants answered using 7-point semantic differential scales with two opposite anchoring phrases $(1=$ very often and 7 = very seldom or never). Negatively worded items were reversescored so that a high score indicated a strong SOC. Items were averaged to calculate the SOC score of each subject, which ranged between 1 and 7 points. When calculating the SOC score, subjects with missing values for more than 3 SOC items were treated as missing. If a subject had 3 or less SOC items with missing values, they were replaced by the mean value of the remaining SOC items for that subject. In this sample, Cronbach's alpha for the SOC scale was 0.85 (see 'Appendix' for the list of 12 SOC items included in the survey's questionnaire).

In terms of dental behaviours, participants reported their pattern of dental attendance on a 3-point scale (never, only for emergencies, regularly for check-ups), their tooth brushing frequency on a 5-point scale (never, less often than every day, once a day, twice a day, more often than twice a day) and their frequency of intake of 6 different sweets and snacks (sugar in tea or coffee; other drinks with sugar added; toffee, liquorice or dried fruit; sweets, hard pastilles or candy without xylitol; chocolate or filled biscuits, and chewing gum without xylitol) on 5-point scales (3 times a day or more often, once or twice a day, 2-5 times a week, more rarely, never). Sugar intake frequency was considered as daily if at least 1 of the 6 items was consumed once a day or more often. For analysis, dental behaviours were dichotomised as follows: dental attendance as 'only for emergencies/never' versus 'regularly for check-ups', tooth brushing frequency as 'once a day or less often' versus 'twice a day or more often', and sugar intake frequency as 'on a daily basis' versus 'less often than daily'.

Clinical oral examinations were conducted identically at baseline and follow-up. Baseline examinations were performed by five dentists using a headlamp, mouth mirror, fibre-optic light and a WHO periodontal probe, with participants seated on a dental 
unit. Follow-up examinations were performed by one of the dentists who participated at baseline. Kappa values for inter- and intraexaminer reliability were 0.87 and 0.95 at tooth level [Suominen-Taipale et al., 2004, 2008]. Teeth were blown dry before inspection and cotton rolls used to keep them dry while inspected. A tooth was recorded as decayed if there was evidence of a caries lesion clearly extending into dentine on any coronal or root surface. The carious lesion had to be cavitated, to have penetrated the fissure and undermined the enamel, or the dentine walls to be clearly softened. Caries increment between baseline and followup was computed by comparing the status of each tooth at baseline with that at follow-up. The 4-year net increment in decayed teeth (net DT increment) was computed for each participant by subtracting the number of reversals from the caries increment.

\section{Statistical Analysis}

Cross-sectional and longitudinal analyses were conducted. The number of decayed teeth was the outcome measure for the cross-sectional analysis. Negative binomial regression was used for modelling this outcome as it was a count variable with overdispersion. Rate ratios were therefore reported. The number of teeth at baseline (in its continuous form) was used as the offset variable in this set of regression models. For the longitudinal analysis, the 4-year net increment in decayed teeth was dichotomised due to the high number of participants with zero increments (90\%). Log-binomial regression was therefore used for modelling incidence of tooth decay and calculating relative risks.

Age and SOC score were treated as continuous variables in all regression models. The assumption of linearity on the log scale was assessed by categorising each explanatory variable into quartiles, replacing the continuous variable with its categorical equivalent, and then, fitting it into the regression models for number of decayed teeth and incidence of tooth decay, respectively. The relationships across quartiles were approximately linear in the two sets of models.

The modelling strategy was first to estimate the crude association of SOC with each outcome and then, gradually adjust for factors that could explain the association. The rationale for the sequence of variable inclusion was to start from confounders (sociodemographic factors) to potential mediators (dental behaviours). Following this modelling strategy, the crude effect of SOC on number of decayed teeth was first estimated. This association was then sequentially adjusted for demographic factors (sex and age) in model 1 , socioeconomic position (education) in model 2 , and dental behaviours (dental attendance, tooth brushing frequency and sugar intake frequency) in model 3. Thereafter, statistical interactions (cross-products) between SOC and sociodemographic factors were examined by assessing their significance when added to model 3 one at a time. The same sequence was followed for testing the association between baseline SOC and incidence of tooth decay.

\section{Results}

Data from 944 dentate adults (426 men and 518 women) were analysed. Their mean age was 48.6 years (SD: 11.9, range: $30-89)$. The baseline sociodemographic char-
Table 1. Description of the sample of Finnish dentate adults $(\mathrm{n}=$ 944)

\begin{tabular}{ll}
\hline Baseline characteristics & Number (\%) \\
\hline Sex & \\
$\quad$ Men & $426(45)$ \\
$\quad$ Women & $518(55)$ \\
Mean age \pm SD, years & $48.6 \pm 11.9$ \\
Education & $250(26)$ \\
$\quad$ Basic & $301(32)$ \\
$\quad$ Secondary & $393(42)$ \\
$\quad$ Higher & $5.5 \pm 0.8$ \\
Mean SOC score \pm SD & $313(33)$ \\
Tooth brushing frequency & $631(67)$ \\
$\quad$ Once a day or less & $366(39)$ \\
$\quad$ Twice a day or more & $578(61)$ \\
Dental attendance & \\
$\quad$ Only for emergencies & $471(50)$ \\
$\quad$ Regularly for check-ups & $473(50)$ \\
Sugar intake frequency & Less often than daily \\
$\quad$ On a daily basis &
\end{tabular}

acteristics of the sample are shown in table 1 . The mean number of decayed teeth at baseline was 0.7 (SD: 2.0, range: $0-23$ ), with $73 \%$ of individuals having no evidence of tooth decay. The 4-year net increment in decayed teeth was 0.1 (SD: 0.4 , range: $0-4$ ), with $90 \%$ of participants having zero increments.

SOC was related to the number of decayed teeth at baseline (table 2). After adjustment for sociodemographic factors (model 2), the number of decayed teeth decreased by $28 \%$ (rate ratio: $0.72,95 \% \mathrm{CI}: 0.59-0.87$ ) for every unit increase in SOC score. The association between SOC and number of decayed teeth was attenuated but remained significant after further adjustment for dental behaviours (model 3). Dental behaviours explained $32 \%$ of this association. Tooth brushing frequency and dental attendance were the dental behaviours significantly related to number of decayed teeth. No significant interactions were found between SOC and sociodemographic factors.

Table 3 shows findings from the longitudinal analysis. Baseline SOC was significantly related to 4-year incidence of tooth decay after sequential adjustment for sex and age (model 1) and additionally for education (model 2). Subjects' risk of having tooth decay decreased by $21 \%$ (relative risk: $0.79,95 \% \mathrm{CI}$ : 0.63-0.98) per unit increase in SOC score. This effect was fully attenuated after further adjustment for dental behaviours. Similar to the cross- 
Table 2. Regression models for the association between SOC and number of decayed teeth in Finnish dentate adults at baseline $(\mathrm{n}=944)$

\begin{tabular}{|c|c|c|c|c|}
\hline Baseline characteristics & $\begin{array}{l}\text { Unadjusted } \\
\text { RR (95\% CI) }\end{array}$ & $\begin{array}{l}\text { Model } 1 \\
\text { RR }(95 \% \text { CI })\end{array}$ & $\begin{array}{l}\text { Model } 2 \\
\text { RR (95\% CI) }\end{array}$ & $\begin{array}{l}\text { Model } 3 \\
\text { RR }(95 \% \text { CI })\end{array}$ \\
\hline SOC score (unit increase) & $0.74(0.6-0.91)^{* *}$ & $0.72(0.59-0.87)^{* *}$ & $0.72(0.59-0.87)^{* *}$ & $0.81(0.68-0.97)^{*}$ \\
\hline \multicolumn{5}{|l|}{ Sex } \\
\hline Men & 1.00 (ref.) & 1.00 (ref.) & 1.00 (ref.) & 1.00 (ref.) \\
\hline Women & $0.38(0.27-0.54)^{* * *}$ & $0.42(0.30-0.58)^{* * *}$ & $0.42(0.31-0.58)^{* * *}$ & $0.61(0.44-0.83)^{* *}$ \\
\hline Age (year increase) & $1.04(1.03-1.06)^{* * *}$ & $1.04(1.03-1.05)^{* * *}$ & $1.02(1.01-1.04)^{* *}$ & $1.03(1.01-1.04)^{* * *}$ \\
\hline \multicolumn{5}{|l|}{ Education } \\
\hline Basic & 1.00 (ref.) & & 1.00 (ref.) & 1.00 (ref.) \\
\hline Secondary & $0.51(0.33-0.78)^{* *}$ & & $0.65(0.42-0.99)^{*}$ & $0.83(0.56-1.25)$ \\
\hline Higher & $0.24(0.16-0.37)^{* * *}$ & & $0.34(0.22-0.52)^{* * *}$ & $0.46(0.31-0.70)^{* * *}$ \\
\hline \multicolumn{5}{|l|}{ Tooth brushing frequency } \\
\hline Once a day or less & 1.00 (ref.) & & & 1.00 (ref.) \\
\hline Twice a day or more & $0.32(0.23-0.45)^{* * *}$ & & & $0.60(0.43-0.82)^{* *}$ \\
\hline \multicolumn{5}{|l|}{ Dental attendance } \\
\hline Only for emergencies & 1.00 (ref.) & & & 1.00 (ref.) \\
\hline Regularly for check-ups & $0.17(0.13-0.24)^{* * *}$ & & & $0.26(0.19-0.36)^{* * *}$ \\
\hline \multicolumn{5}{|l|}{ Sugar intake frequency } \\
\hline Less often than daily & 1.00 (ref.) & & & 1.00 (ref.) \\
\hline On a daily basis & $1.71(1.21-2.42)^{* *}$ & & & $1.28(0.95-1.73)$ \\
\hline
\end{tabular}

Negative binomial regression models were fitted and rate ratios (RR) reported. ${ }^{*} \mathrm{p}<0.05 ;{ }^{* *} \mathrm{p}<0.01 ;{ }^{* *} \mathrm{p}<0.001$.

Table 3. Regression models for the association between baseline SOC and 4-year incidence of tooth decay in Finnish dentate adults $(\mathrm{n}=944)$

\begin{tabular}{|c|c|c|c|c|}
\hline Baseline characteristics & $\begin{array}{l}\text { Unadjusted } \\
\text { RR (95\% CI) }\end{array}$ & $\begin{array}{l}\text { Model } 1 \\
\text { RR (95\% CI) }\end{array}$ & $\begin{array}{l}\text { Model } 2 \\
\text { RR (95\% CI) }\end{array}$ & $\begin{array}{l}\text { Model } 3 \\
\text { RR (95\% CI) }\end{array}$ \\
\hline SOC score (unit increase) & $0.81(0.65-1.01)$ & $0.78(0.63-0.97)^{*}$ & $0.79(0.63-0.98)^{*}$ & $0.81(0.64-1.02)$ \\
\hline \multicolumn{5}{|l|}{ Sex } \\
\hline Men & 1.00 (ref.) & 1.00 (ref.) & 1.00 (ref.) & 1.00 (ref.) \\
\hline Women & $0.50(0.34-0.74)^{* * *}$ & $0.49(0.33-0.72)^{* * *}$ & $0.50(0.34-0.73)^{* * *}$ & $0.60(0.40-0.91)^{*}$ \\
\hline Age (year increase) & $1.04(1.03-1.06)^{* * *}$ & $0.99(0.97-1.01)$ & $0.99(0.97-1.00)$ & $0.99(0.97-1.01)$ \\
\hline \multicolumn{5}{|l|}{ Education } \\
\hline Basic & 1.00 (ref.) & & 1.00 (ref.) & 1.00 (ref.) \\
\hline Secondary & $1.20(0.74-1.94)$ & & $1.02(0.61-1.72)$ & $1.12(0.67-1.88)$ \\
\hline Higher & $0.99(0.62-1.60)$ & & $0.90(0.53-1.55)$ & $1.09(0.63-1.88)$ \\
\hline \multicolumn{5}{|l|}{ Tooth brushing frequency } \\
\hline Once a day or less & 1.00 (ref.) & & & 1.00 (ref.) \\
\hline Twice a day or more & $0.50(0.34-0.72)^{* * *}$ & & & $0.64(0.43-0.95)^{*}$ \\
\hline \multicolumn{5}{|l|}{ Dental attendance } \\
\hline Only for emergencies & 1.00 (ref.) & & & 1.00 (ref.) \\
\hline Regularly for check-ups & $0.56(0.39-0.81)^{* *}$ & & & $0.64(0.44-0.93)^{*}$ \\
\hline \multicolumn{5}{|l|}{ Sugar intake frequency } \\
\hline Less often than daily & 1.00 (ref.) & & & 1.00 (ref.) \\
\hline On a daily basis & $1.27(0.87-1.84)$ & & & $1.11(0.76-1.62)$ \\
\hline
\end{tabular}

Log-binomial regression models were fitted and relative risks $(\mathrm{RR})$ reported. ${ }^{*} \mathrm{p}<0.05 ;{ }^{* *} \mathrm{p}<0.01 ;{ }^{* *} \mathrm{p}<0.001$. 
sectional findings, tooth brushing frequency and dental attendance were the only dental behaviours significantly related to incidence of tooth decay. There were no significant interactions between SOC and sociodemographic factors.

\section{Discussion}

This is the first prospective study on the association of SOC with clinical oral health in adults. SOC was a predictor of 4-year incidence of tooth decay, irrespective of subjects' sociodemographic background. Each higher point in the SOC score was associated with around $20 \%$ decrease in the risk of having tooth decay. This finding is in line with previous studies showing SOC as an independent predictor of various aspects of adult health [Poppius et al., 1999; Kivimäki et al., 2000; Suominen et al., 2001; Poppius et al., 2003; Surtees et al., 2003; Kouvonen et al., 2008, 2010] and a recent oral health study in adolescents where stronger SOC predicted better health perceptions and quality of life 6 months later [Baker et al., 2010].

This study also shows that dental behaviours have a potential but not equally strong role in explaining the effect of SOC on 4-year incidence of tooth decay. First, the effect of SOC on incidence of tooth decay was fully accounted for by dental behaviours. This finding provides stronger evidence than a previous cross-sectional study among the same population [Bernabé et al., 2010] to support the importance of the behavioural pathway between SOC and dental caries. However, it is worth noticing that we could not assess alternative mechanisms for the SOC effect such as emotional processes and stress-related physiological responses [Antonovsky, 1987, 1996]. Medical researchers have shown that SOC correlates with emotional states [Kivimäki et al., 2002; Konttinen et al., 2008] and health biomarkers [Almedom et al., 2005; Lindfors et al., 2006]. Therefore, further research is needed to determine the relative contribution of the three alternative mechanisms in relation to dental caries. Second, tooth brushing frequency and dental attendance were the only dental behaviours related to incidence of tooth decay in the fully adjusted model, which supports their role as mediators of the relationship between SOC and caries development. Regular dental attendance may help explaining the relationship between SOC and tooth decay because it provides individuals with access not only to preventive measures (stopping or delaying caries initiation) but also to restor- ative treatment (replacing decayed with filled teeth). Although sugar intake frequency was not related to incidence of tooth decay, we cannot rule it out as another intermediate factor yet. The low cut-off point used to operationalise sugar intake frequency (i.e. daily consumption) may have masked its effect by aggregating low, moderate and high consumers into one single group. Therefore, it is likely that different results may be found when using a higher threshold to define sugar intake frequency.

Subject to replication in different populations, the present findings imply that policies and interventions to promote oral health may benefit from considering the psychosocial characteristics encompassed by the SOC construct. To date, there are no evidence-based standard interventions to strengthen adult SOC at a population level. According to the salutogenesis theory, SOC is shaped by three types of life experiences during the first decades of life, namely consistency, under-/overload balance and participation in socially valued decision-making [Antonovsky, 1987, 1996]. Therefore, it may be possible to strengthen SOC by early life interventions, with the former recently shown in a school program where changes in SOC were accompanied by improvements in tooth brushing behaviour [Ayo-Yusuf et al., 2008, 2009]. However, we still need to fully understand the context in which a strong SOC is developed to be able to extend this discussion to public health policy and practice.

Some limitations of this study need to be addressed. First, our analytical sample included slightly younger and more educated participants than the baseline sample of the Health 2000 Survey. Therefore, our findings represent valid relationships between the variables of interest but cannot be inferred to the Finnish adult population. Second, due to a clerical error SOC was assessed using 12 of the 13 items of the original short SOC scale. Despite being different in only one item from the original scale, it is possible that this modified instrument, widely used among Finnish adults [Savolainen et al., 2004, 2005; Bernabé et al., 2009a; Savolainen et al., 2009; Bernabé et al., 2010], may have measured a phenomenon that is similar but not identical to Antonovsky's [1987] SOC construct. However, this abbreviated SOC scale has good structural validity and internal consistency [Bernabé et al., 2009b]. In addition, a 4-year prospective study found similar results for the association between SOC and health when using the SOC-13 or even a shorter 6-item version [Kivimäki et al., 2000]. Third, net DT increment was preferred over net DMFT increment in spite of the fact that the latter is the standard measure in longitudinal studies 
of dental caries [Beck et al., 1997; Broadbent and Thomson, 2005]. This was done because net DMFT increment masked the opposite effects of SOC on DMFT components; SOC was inversely related to net DT and MT increments but positively (though not significantly) related to net FT increment. These effects cancelled each other out when using net DMFT increment. In addition, few participants experienced tooth decay during follow-up, which may have reduced variability in the outcome. Although the number of caries events could have been increased by using diagnostic aids (such as radiographs) or recording early carious lesions, these approaches are neither feasible nor fully reliable in large epidemiological surveys. Fourth, this study assessed only two specific time points in the life course. This is the simplest scenario in longitudinal data analysis and unlikely to represent the complex relationship between SOC and dental caries, particularly to examine if changes in SOC are related to changes in caries levels for which panel data are required. Therefore, our findings need to be corroborated by further studies in which both SOC and dental caries are measured more often over the lifespan.

In conclusion, this 4 -year prospective study suggests that SOC predicts incidence of tooth decay in adults, and that dental behaviours may help explaining why adults with strong SOC have lower risk of developing tooth decay compared to those with weak SOC.

\section{Acknowledgements}

The Health 2000 Survey was organised by the National Institute for Health and Welfare (THL), formerly the National Public Health Institute (KTL), of Finland (http://www.terveys2000.fi/indexe.html) and partly supported by the Finnish Dental Society Apollonia and the Finnish Dental Association. The Follow-Up Study on Finnish Adults' Oral Health was organised and funded by the National Institute for Health and Welfare and the Social Insurance Institution of Finland (KELA).

\section{Disclosure Statement}

The authors declare that they have no relevant financial relationships or any conflict of interests.

\section{Appendix}

List of the 12 items (answering options) of the SOC scale used in this study. For comparability with previous studies, the number of each item refers to its position in the original SOC scale with 29 items [Antonovsky, 1987].

(4) Do you have the feeling that you don't really care what goes on around you?

$$
\text { Very seldom or never Very often }
$$

(5) Has it happened in the past that you were surprised by the behaviour of people whom you thought you knew well?
Never happened
Always happened

(6) Has it happened that people whom you counted on disappointed you? Never happened Always happened

(8) Until now your life has had: No clear goals or purpose at all Very clear goals and purpose

(9) Do you have the feeling that you're being treated unfairly? Very often Very seldom or never

(12) Do you have the feeling that you're in an unfamiliar situation and don't know what to do?

Very often Very seldom or never

(16) Doing the things you do every day is: A source of deep pleasure and A source of pain and boredom satisfaction

(19) Do you have very mixed-up feelings and ideas? Very often Very seldom or never

(25) Many people - even those with a strong character - sometimes feel like sad sacks (losers) in certain situations. How often have you felt this way in the past?
Never
Very often

(26) When something happened, you have generally found that: you over- or underestimated its you saw things in the right importance proportion

(28) How often do you have the feeling that there's little meaning in the things you do in your daily life?

Very often Very seldom or never

(29) How often do you have feelings that you're not sure you can keep under control?

Very often Very seldom or never

\section{References}

-Almedom AM, Teclemichael T, Romero LM, Alemu Z: Postnatal salivary cortisol and sense of coherence (SOC) in Eritrean mothers. Am J Hum Biol 2005;17:376-379.

Antonovsky A: Unravelling the Mystery of Health: How People Manage Stress and Stay Well. San Francisco, Jossey-Bass, 1987.

Antonovsky A: The salutogenic model as a theory to guide health promotion. Health Promot Int 1996;11:11-18.
Aromaa A, Koskinen S: Health and Functional Capacity in Finland. Baseline Results of the Health 2000 Health Examination Survey. Helsinki, Publications of the National Public Health Institute B12/2004, 2004. http:// www.terveys2000.fi/julkaisut/baseline.pdf.

-Ayo-Yusuf OA, Reddy PS, van den Borne BW: Adolescents' sense of coherence and smoking as longitudinal predictors of self-reported gingivitis. J Clin Periodontol 2008;35:931-937.
Ayo-Yusuf OA, Reddy PS, van den Borne BW: Longitudinal association of adolescents' sense of coherence with tooth-brushing using an integrated behaviour change model. Community Dent Oral Epidemiol 2009;37: 68-77.

Baker SR, Mat A, Robinson PG: What psychosocial factors influence adolescents' oral health? J Dent Res 2010;89:1230-1235. 
Beck JD, Lawrence HP, Koch GG: Analytic approaches to longitudinal caries data in adults. Community Dent Oral Epidemiol 1997;25:42-51.

-Bernabé E, Kivimaki M, Tsakos G, SuominenTaipale AL, Nordblad A, Savolainen J, Uutela A, Sheiham A, Watt RG: The relationship among sense of coherence, socio-economic status, and oral health-related behaviours among Finnish dentate adults. Eur J Oral Sci 2009a;117:413-418.

-Bernabé E, Tsakos G, Watt RG, Suominen-Taipale AL, Uutela A, Vahtera J, Kivimaki M: Structure of the sense of coherence scale in a nationally representative sample: the Finnish Health 2000 survey. Qual Life Res 2009b;18:629-636.

-Bernabé E, Watt RG, Sheiham A, Suominen-Taipale AL, Uutela A, Vehkalahti MM, Knuuttila M, Kivimaki M, Tsakos G: Sense of coherence and oral health in dentate adults: findings from the Finnish Health 2000 survey. J Clin Periodontol 2010;37:981-987.

-Bernabé E, Watt RG, Sheiham A, Suominen AL, Vehkalahti MM, Nordblad A, Uutela A, Kivimaki M, Tsakos G: Childhood socioeconomic position, adult sense of coherence and tooth retention. Community Dent Oral Epidemiol 2012;40:46-52.

Broadbent JM, Thomson WM: For debate: problems with the DMF index pertinent to dental caries data analysis. Community Dent Oral Epidemiol 2005;33:400-409.

Heistaro S: Methodology Report - Health 2000 Survey. Helsinki, Publications of the National Public Health Institute B6/2005, 2008. http://www.terveys2000.fi/doc/methodologyrep.pdf.

Kivimäki M, Elovainio M, Vahtera J, Nurmi JE, Feldt T, Keltikangas-Jarvinen L, Pentti J: Sense of coherence as a mediator between hostility and health: seven-year prospective study on female employees. J Psychosom Res 2002;52:239-247.
Kivimäki M, Feldt T, Vahtera J, Nurmi JE: Sense of coherence and health: evidence from two cross-lagged longitudinal samples. Soc Sci Med 2000;50:583-597.

Konttinen H, Haukkala A, Uutela A: Comparing sense of coherence, depressive symptoms and anxiety, and their relationships with health in a population-based study. Soc Sci Med 2008;66:2401-2412.

Kouvonen AM, Vaananen A, Vahtera J, Heponiemi T, Koskinen A, Cox SJ, Kivimaki M: Sense of coherence and psychiatric morbidity: a 19-year register-based prospective study. J Epidemiol Community Health 2010; 64:255-261.

Kouvonen AM, Vaananen A, Woods SA, Heponiemi T, Koskinen A, Toppinen-Tanner S: Sense of coherence and diabetes: a prospective occupational cohort study. BMC Public Health 2008;8:46.

Lindfors P, Lundberg O, Lundberg U: Allostatic load and clinical risk as related to sense of coherence in middle-aged women. Psychosom Med 2006;68:801-807.

Lindmark U, Hakeberg M, Hugoson A: Sense of coherence and oral health status in an adult Swedish population. Acta Odontol Scand 2011a;69:12-20.

-Lindmark U, Hakeberg M, Hugoson A: Sense of coherence and its relationship with oral health-related behaviour and knowledge of and attitudes towards oral health. Community Dent Oral Epidemiol 2011b;39:542-553.

Lindmark U, Stegmayr B, Nilsson B, Lindahl B, Johansson I: Food selection associated with sense of coherence in adults. Nutr J 2005;4:9.

Poppius E, Tenkanen L, Hakama M, Kalimo R, Pitkanen T: The sense of coherence, occupation and all-cause mortality in the Helsinki Heart Study. Eur J Epidemiol 2003;18:389393.
Poppius E, Tenkanen L, Kalimo R, Heinsalmi P: The sense of coherence, occupation and the risk of coronary heart disease in the Helsinki Heart Study. Soc Sci Med 1999;49:109-120.

Savolainen J, Knuuttila M, Suominen-Taipale L, Martelin T, Nordblad A, Niskanen M, Uutela A: A strong sense of coherence promotes regular dental attendance in adults. Community Dent Health 2004;21:271-276.

-Savolainen J, Suominen-Taipale A, Uutela A, Aromaa A, Harkanen T, Knuuttila M: Sense of coherence associates with oral and general health behaviours. Community Dent Health 2009;26:197-203.

-Savolainen J, Suominen-Taipale AL, Uutela AK, Martelin TP, Niskanen MC, Knuuttila ML: Sense of coherence as a determinant of toothbrushing frequency and level of oral hygiene. J Periodontol 2005;76:1006-1012.

Suominen-Taipale AL, Nordblad A, Vehkalahti M, Aromaa A: Suomalaisten Aikuisten Suunterveys, Terveys 2000 - Tutkimus. Helsinki, Publications of the National Public Health Institute B16/2004, 2004. http:// www.ktl.fi/attachments/suomi/julkaisut/ julkaisusarja_b/2004b16.pdf.

Suominen-Taipale AL, Nordblad A, Vehkalahti M, Aromaa A: Oral Health in the Finnish Adult Population. Health 2000 Survey. Helsinki, Publications of the National Public Health Institute B 25/2008, 2008. http:// www.ktl.fi/attachments/suomi/julkaisut/ julkaisusarja_b/2008/2008b25.pdf.

Suominen S, Helenius H, Blomberg H, Uutela A, Koskenvuo M: Sense of coherence as a predictor of subjective state of health: results of 4 years of follow-up of adults. J Psychosom Res 2001;50:77-86.

Surtees PG, Wainwright N, Luben R, Khaw KT, Day N: Sense of coherence and mortality in men and women in the EPIC-Norfolk United Kingdom prospective cohort study. Am J Epidemiol 2003;158:1202-1209. 